\title{
Combining Scenario Planning and
}

\section{Multi-Criteria Decision Analysis in Practice}

\author{
Gilberto Montibeller \\ Operational Research Group, Department of Management, \\ London School of Economics and Political Science, England, UK \\ Haidee Gummer, Daniele Tumidei \\ Kingston Business School \\ Kingston University, London, England, UK
}

Working Paper LSEOR 07.92

ISBN: 978-0-85328-047-7 


\section{First published in Great Britain in 2007 by the Operational Research Group, Department of Management London School of Economics and Political Science}

Copyright $\odot$ The London School of Economics and Political Science, 2007

The contributors have asserted their moral rights.

All rights reserved. No part of this publication may be reproduced, stored in a retrieval system, or transmitted in any form or by any means, without the prior permission in writing of the publisher, nor be circulated in any form of binding or cover other than that in which it is published.

Typeset, printed and bound by:

The London School of Economics and Political Science

Houghton Street

London WC2A 2AE 


\title{
Combining Scenario Planning and Multi-Criteria Decision Analysis in Practice
}

\author{
Gilberto Montibeller $^{1 \mathrm{a}}$, Haidee Gummer $^{\mathrm{b}}$ and Daniele Tumidei ${ }^{\mathrm{b}}$ \\ ${ }^{a}$ Operational Research Group, Dept. of Management, London School of Economics, UK. \\ ${ }^{\mathrm{b}}$ Kingston Business School, Kingston University, London, UK
}

\begin{abstract}
The integrated use of Scenario Planning and Multi-Criteria Decision Analysis (MCDA) has been advocated as a powerful combination for providing decision support in strategic decisions. Scenario Planning helps decision makers in devising strategies and thinking about possible future scenarios; while MCDA can support an indepth performance evaluation of each strategy, as well as in the design of more robust and better options. One of the frameworks proposed recently, by Goodwin \& Wright, suggests the use of scenario planning with multi-attribute value theory, a mathematically simple, yet extensively researched and widely employed multi-criteria method. However, so far, such framework has been presented only using hypothetical problems. In this paper we describe two case-studies where this approach was used to support real-world strategic decisions. We discuss the challenges and limitations we encountered in applying it; and suggest some possible improvements that could be made to such framework.
\end{abstract}

Key-words: scenario planning, multi-criteria decision analysis, strategic decision making, risk and uncertainty.

"[Under uncertainty] there is no scientific basis on which to form any calculable probability whatever. We simply do not know. Nevertheless, the necessity for action and for decision compels us as practical men to do our best to overlook this awkward fact (...)."

John Maynard Keynes (1937)

\footnotetext{
1 Corresponding author: Dr Gilberto Montibeller - Operational Research Group, Dept. of Management, London School of Economics, Houghton Street, London WC2A 2AE, England, UK

E-mail: g.montibeller@1se.ac.uk
} 


\section{Introduction}

The integrated use of Scenario Planning and Multi-Criteria Decision Analysis (MCDA) has been advocated as a powerful combination for decision support in strategic decisions. The two methodologies seem to play a complementary role with each other.

Scenario Planning (SP), a widely employed methodology for supporting strategic decision making, employs the use of imaginary future scenarios to help decision makers think about the main uncertainties they face, and devise strategies to cope with those uncertainties (see van der Hijden, 2005). SP lacks, however, a more detailed phase of evaluation of options, where the performances of those strategies are appraised (Stewart, 1997; Goodwin \& Wright, 2001; Durbach \& Stewart, 2003). Besides, these scenarios are not, necessarily, a mutually exclusive and exhaustive set of future states (Goodwin \& Wright, 2001; Stewart, 1997), what prevents the use of standard decision trees to find the best option (where probabilities are attached to each possible state and expected outcomes can be calculated - see Clemen \& Reilly, 2001).

On the other hand, Multi-Criteria Decision Analysis (MCDA) is a methodology designed for evaluating options taking into account decision-makers' multiple, and often conflictive, objectives (for an overview, see Belton \& Stewart, 2002 and Goodwin \& Wright, 2004). It also provides a strong framework for supporting the design of better and more robust options, as it permits decision makers to analyse the performance of each strategy on each of the organisation's objectives and thus identify its weaknesses and opportunities for improvement. Thus it seems natural that proposals for combining the two methodologies have been made in the literature, as it may lead to SP interventions where strategies are appraised in a more detailed way.

With this intent, some approaches have been already proposed. Saaty \& Kearnes (1985) suggest the use of the Analytic Hierarchy Process in the context of SP, but scenarios there are conceptualised as options that decision makers wish to happen in the future. Durbach \& Stewart (2003) have employed a goal programming model to make a multi-criteria evaluation of options considering different scenarios. Belton and Stewart (2002) discuss the potential use of MCDA and scenario planning. Stewart $(1997 ; 2005)$ presents several technical issues about this integration and provides a thoughtful discussion on how it could be made. Finally, Goodwin \& Wright (2001) suggest the use of a multi-attribute value function to assess strategies according to different scenarios. It is this latter approach that we are considering in this paper, as it employs a mathematically simple (yet widely researched and extensively employed) multicriteria method; 
thus avoiding a sophisticated mathematical analysis, much in the spirit of scenario planning. However, as far as we know, their approach has been presented only using hypothetical problems.

Thus the aim of this paper is to discuss our experience in putting the Goodwin \& Wright (G\&W) approach into practice. It describes two case-studies where their method was used to support real-world decisions, and discusses the challenges and limitations we encountered in applying it. The paper also suggests some possible improvements that could be made to such an approach.

The next section briefly presents the Goodwin \& Wright approach and discusses some of the open questions we have about the method. The following two sections describe each case study in detail and reflect on our experience of attempting to put the approach into practice. The paper then presents some suggestions for improving their method, drawn from our experience in the case studies. Some general conclusions are discussed in the final section.

\section{The Goodwin \& Wright (G\&W) Approach}

The G\&W approach is an extension of a traditional MAVT analysis, considering future scenarios. It can be described as a set of steps:

- Define a set of $n$ strategic options $\left(\mathrm{a}_{\mathrm{i}}\right)$;

- Define a set of $m$ future scenarios $\left(\mathrm{s}_{\mathrm{j}}\right)$;

- Each decision alternative is a combination of a strategic option in a given scenario $\left(\mathrm{a}_{\mathrm{i}}-\mathrm{S}_{\mathrm{j}}\right)$;

- Define a value tree, which represents the fundamental objectives of the organisation;

- Measure the achievement of each decision alternative $\mathrm{a}_{\mathrm{i}}-\mathrm{S}_{\mathrm{j}}$ on each objective of the value tree using a 100-0 value scoring;

- Elicit the weights of each objective in the value tree using swing weighting (anchoring on the worst and best decision alternatives);

- Aggregate the performances of each decision alternative $\mathrm{a}_{\mathrm{i}}-\mathrm{s}_{\mathrm{j}}$ using the weights attached to the objectives in the value tree, finding an overall score for the decision alternative.

The hypothetical case presented in Goodwin \& Wright (2001) can illustrate the method. It assumes that a national mail company is considering its future under two scenarios: Dog Fight $\left(s_{1}\right)$ where the company loses its monopoly and Mail Mountain $\left(s_{2}\right)$ where it retains it. Three strategies are available: maintain the Status Quo $\left(a_{1}\right)$, investment in R\&D $\left(a_{2}\right)$ and Diversification 
$\left(a_{3}\right)$. Five objectives were considered in the value tree: short and long term profitability, market share, growth and flexibility.

Each decision alternative is ranked on each objective, as exemplified in Table 1.a for long term profit, and then its relative value is elicited (Table 1.b). Using the same procedure for the other objectives, eliciting weights, and aggregating the partial performances, it is possible to find an overall value for each alternative (Table 1.c). In this problem, $R \& D\left(a_{2}\right)$ seems to be the best option: $\mathrm{a}_{1}$ is dominated by the other two strategies; and $\mathrm{a}_{2}$ practically dominates (Hammond et al., 1998) strategy $a_{3}$, as both have similar performances under Dog Fight but $\mathrm{a}_{2}$ is much stronger under Mail Mountain.

Place Table 1 about here.

The G\&W approach is quite appealing, as it employs a mathematically simple, but well-founded and widely-researched framework (Multi-Attribute Value Theory, for details see Belton \& Stewart, 2002). It also does not attempt to put probabilities on each scenario, or aggregate performances across scenarios which, in our opinion, would go against the spirit of SP.

However there are several open research questions in applying this approach in practice. Does the method work well if there were a larger number of options and/or scenarios? What kind of elicitation burden does it place on decision-makers? How could one deal with situations where there is not a clear dominant option? What if weights / objectives were different for different scenarios? Could it be employed for improving strategies? Following these concerns, we attempted to put the approach into practice, as described in the next section.

\section{The Case Studies}

With the aim of employing the G\&W method in practice, we selected two distinctive strategic problems and attempted to utilise it to support the decision-making process. We deliberately took an inductive approach, without the statement of rigid hypothesis (for details see Bryman \& Bell, 2003), but our aims were:

i. to establish whether the method could feasibly be employed in practice;

ii. to identify any difficulties encountered in applying the method;

iii. to find if decision makers perceived the method to be useful as a form of decision support.

In both cases we employed Action-Research, a research method which has been advocated as suitable for decision support methodologies - for an interesting discussion on using such 
research method in this type of setting see Eden (1995) and Finlay (1998) - and has also been increasingly employed in multi-criteria decision analysis interventions (Montibeller, 2005). Therefore each intervention had an action objective (supporting strategic decision making) as well as the research objectives stated in the previous paragraph.

We employed participant observation and, after the intervention, asked the decision-makers to reflect on their experience. For both interventions we utilised VISA (www.simul8.com/visa) a software for MCDA which permits easy visualisation of results and visual interactive modelling (including the refining of scores and weights - see Brugha, 2004). We now describe each intervention in the following two sub-sections.

\section{Case Study 1 - The English Provincial Broker's Future}

\section{The Decision Problem}

Our client, SIB, is an established provincial broker, with nearly 30 -years experience of providing insurance products via a high-street presence, built upon personal service and impartial knowledge to their clients. Both SIB's Directors were nearing retirement and focusing their strategies in the short-term; with current office leases expiring in 5-7 years and exit strategies being researched; although they were considering employing a senior executive to run the business in the longer-term. They did not actively pursue new clients via marketing activities; such business relies totally on word-of-mouth and gaining additional business from cross-selling to existing clients.

Due to vast changes in the competitive landscape in Britain, the insurance industry was assessing its business risks. The Financial Services Authority (FSA) had recently entered the industry as the new regulatory body and required every company to hold a licence to trade from January 2005. Industry sources predicted, when this case was developed (2004) that approximately half the number of independent brokers would be trading on the high-street from this date.

During 2004 there was much speculation as to the future direction of the industry as it continued to consolidate, with insurance companies re-assessing secondary agents (brokers) and overseas call-centres. This potentially offered many opportunities, and high-street brokers were openly encouraged to sell to larger firms. Brokers needed to ensure their chosen strategic direction best suited their goals and aspirations, especially as the predicted costs of obtaining a licence would amount to $4 \%-18 \%$ of their annual turnover, potentially eclipsing profits. 
Given this high level of uncertainty and the importance of the success of the company for its Directors' well-being, they asked for our advice. It seemed to us that scenario planning and multi-criteria decision analysis could be potentially useful in this decision problem.

\section{The Decision Model}

In the first instance, a value tree representing the SIB's fundamental objectives (Figure 1 exhibit A) was created, and its structural properties were checked (see Belton and Stewart, 2002). Following a value-focused thinking approach (Keeney, 1992) five strategic options were created in order to achieve such objectives: immediately sell the business, maintain the existing business for the next 5-7 years, merge with another broker, purchase another broker, or grow the existing business aiming for diversification.

Place Figure 1 about here.

With mixed views in the industry about the future, our team helped the decision-makers to create three scenarios, utilising existing knowledge and secondary data from the industry and its specialised media: Direct Future (the industry continues in its trend for direct services, reducing the need for brokers and further increasing consumer choice over the next five years); Symbiotic Future (brokers flourish in a reinvigorated industry, driven by increased collaboration with insurers, encouraging long-term relationships); Network-Based Future (reduction in high street presence, but increased power through a broker network). The qualitative performance of each option in each scenario is presented in Table 2, a standard scenario planning table.

Place Table 2 about here.

Following the G\&W approach, we asked the decision-makers to first rank, then score using a 0100 value scale, each decision alternative (i.e., a pair strategic option-scenario, $\mathrm{a}_{\mathrm{i}}-\mathrm{s}_{\mathrm{j}}$ ) on each fundamental objective. The results from this scoring are shown in Figure 2.

Place Figure 2 about here.

Swing weights were then elicited from the Directors, anchoring on the best alternative (Symbiotic-Maintain, SM in Figure 2) and worst alternative (Network Based - Sell, NBS in Figure 2) - these swings are shown in Figure 1 (exhibit B) as well as the normalised weights (exhibit C). The results, also presented in Figure 1 (exhibit D), show that the strategy of maintaining the existing business (S_Maintain) is the dominant option in the three scenarios: Direct Future (D); Symbiotic Future (S) and Network-Based Future (NB). 


\section{Reflection on the Intervention}

It was clearly possible to employ the method in practice but problem structuring and model building did take some time. The most striking difficulty in this case study was to elicit the performances of each strategy in each scenario (to obtain the values shown in Figure 2). It was difficult for the Directors, initially, to understand this kind of evaluation and we had to repeat the process several times. Our attempt of using VISA for this elicitation was also unfruitful, and made the task even harder, as it was really difficult to understand the meaning of each alternative there (notice how cluttered exhibit $\mathrm{E}$ is in Figure 1).

SIB's Directors found the learning associated with creating the model (scenarios, strategic options and the value tree) very useful as it forced them to take a different perspective on the industry and to properly evaluate their objectives. They found the latter stages of comparing alternatives to attributes as an unnecessarily "academic" exercise as the process had, in their view, already indicated the strategic direction they should follow - and therefore we had reached a requisite model (Phillips, 1984).

\section{The Day After in the English Broker Decision}

Following our intervention, SIB chose to apply for accreditation and maintain their existing business (which was the strongest option according to the model) until the uncertainties could be evaluated more accurately. Three years on, insurance companies are further reviewing their direct/call centre business and are keen to hold onto and encourage brokers in creating a more cohesive working arrangement. By maintaining their previous business model, SIB have benefited from the changes. Having obtained a licence, they can justify being in business to clients/insurers and push ahead with more confidence; also, due to the reduction in broker numbers, their level of business has increased organically. Their business with insurers and the job security available to their staff is more certain and SIB's Directors are now considering growing their businesses due to the security and opportunities that lie ahead.

Insurers are still dealing direct to customers but this is not the main focus. The symbiotic future is occurring with a more cohesive structure with insurers now concentrating on fewer brokers to get better value from them. Networks are still growing, and some insurers who purchased broker chains are operating them as a franchise, offering restricted products. It is still unclear as to the exact future direction of the industry, but at least the basis for business is more secure and the playing field is more transparent now. 


\section{Case Study 2 - The Warehouse Development in Casemurate, Italy}

\section{The Decision Problem}

Our client in this second case study was ACT properties. Its core business is to buy plots of land in Italy for logistics or retail property development, aiming industrial or commercial use. They also invest in buying options for plots of land for which it is possible to obtain a change of destination, from farming to industrial or commercial development.

In 2004 the company purchased an option for the duration of 1.5 years on $25 \mathrm{Ha}$ of farm land in Casemurate, Italy for $€ 160,000$, which represents $10 \%$ of the total purchase price. The company's plans were to develop the land with logistic warehouses for which the company had a demand. Alternatively, it could abandon the deal and lose/resell the residual value of the option.

The area is currently farm land and the local authorities could change its destination within the periodical revision of the borough zoning plan, which occurs every 5 years. The most recent zoning revision was due to be completed by the end of 2005. Before purchasing the option, ACT had consulted the local authorities, who were initially favourable to change the destination from farming to industrial, but there were uncertainties to whether the planning permission would actually be granted.

Due to these uncertainties, the Director of ACT asked for our help with this decision. Interestingly, he felt unable to attach probabilities to the possibility of planning permission (which could have led us to develop a decision tree) thus again we decided to use scenario planning and multi-criteria analysis for providing decision support.

\section{The Decision Model}

From the setting described in the previous section, two scenarios were foreseen:

- No Change of Destination (NC): The local authorities do not allow any change of destination and the area remains farm land (development possibilities are limited).

- Change of Destination (CD): The local authorities allow a total or partial change of destination (i.e. from $5 \mathrm{Ha}$ to $25 \mathrm{Ha}$, thus logistics can be developed).

In order to ensure that all possible options have been identified, Ansoff's box was used as a strategic management tool for option generations (Ansoff, 1988), producing five strategic options: 
Withdrawal (Wth): Sell the residual value of the deal and abandon it. For the purpose of this analysis it is assumed that ACT will be able to at least recover the option cost and therefore receive a profit value of zero.

Penetration (Pen) (buy some of the land): Buy key plots of land only and lose some of the option money in 1.5 years (i.e. 5Ha). Penetration could produce a profit of $€ 500,000$ with a change of destination of the purchased key plots, or no profit, if the change of destination is not allowed.

Consolidation (Con) (buy all of the land): Buy all of the land and plan to develop some or all of it. Consolidation would produce a profit of $€ 2,925,000$ if the destination was changed, but none if the destination was unchanged.

Use existing competencies (Exs): Buy all of the land in 1.5 years, apply for countryside houses (the owner of $6 \mathrm{Ha}$ of land has a right to build a house) or plan for a countryside restaurant with a large park. Either of these developments could produce a total profit of $€ 500,000$ in any scenario.

New competencies (Ncn): Buy all of the land in 1.5 years for vehicle depot or display area (van, caravans, trucks, tractors), or a gardening centre, or countryside activities. These strategies could produce a profit of $€ 200,000$ in each scenario.

(Profits are estimates from ACT's Director, but have been slightly modified in this paper due to a confidentiality agreement.)

As it is standard in scenario planning, the qualitative performance of each strategy in each scenario is described in Table 3. The company had identified its strategic objectives which are essential to running the business effectively, these were structured as a value tree as shown in Figure 3 (exhibit A). The Profitability level of a deal is the main driver for ACT. Profit in real estate is almost always relatively long term ( 2 to 4 years). Relevance to Core Business of a deal is another important factor on which ACT bases its investing decisions, as they are not primarily interested in hotels, restaurants or residential developments. Liquidity is essential in property deals and needs careful monitoring, since property investments tend to be extremely cash demanding and highly illiquid. Short Term Liquidity is needed for buying options, paying consultants fees and buying the land which needs to be acquired or developed. Long Term Liquidity is usually generated by the sale of a deal and is represented by the profit of a deal once the loans have been repaid to the shareholders or the banks. The structural properties required for a value tree (see Belton and Stewart, 2002) were checked and confirmed. 
Place Figure 3 and Table 3 about here.

Value functions were elicited for each quantitative attribute, for example profitability as shown in Figure 3 (exhibit B). Weights were elicited using swing weights (exhibit C) which were then normalised (Exhibit D) and each alternative was evaluated on each attribute (as illustrated for profitability, exhibit E). Analysing the result (exhibit F, change of destination [CD] on the left, no change of destination [ $\mathrm{NC}]$ on the right), consolidation was the best strategic option under the change of destination scenario (CD_Con) and existing competencies the best one under the no change of destination scenario (NC_Exs).

\section{Reflection on the Intervention}

At this stage, the decision-maker found the results quite unhelpful. As there was not a dominating option, or a practically dominating one, he was confronted with a difficult choice and asked if we could provide further guidance with the decision he had to make. Consolidation performed really well in one scenario, but was an extremely weak option if the other scenario happened, so it seemed to him risky. Even more worrisome, he mentioned the need for addressing different priorities under different scenarios. These concerns were issues that the Goodwin \& Wright approach could not address.

Given the lack of a requisite model (Phillips, 1984) at this point, we decided to continue the decision support, but incorporated some extra tools that could address such issues. These suggestions, which can be applied to the G\&W approach in general, are discussed in the next section and illustrated with the Casemurate case.

\section{Extending the Goodwin \& Wright Approach}

In this section we present some suggestions for extending the G\&W approach, drawn from our experience of applying it in the case studies just described. They deal with the need of addressing different organisation's priorities in distinctive scenarios; of reducing the cognitive burden involved in eliciting performances of strategies; and of assessing risk and robustness of options, in order to devise improved strategies.

\section{Dealing with Different Priorities across Scenarios}

The first change we propose in the Goodwin \& Wright approach is to use, if necessary, different weights for each scenario, i.e., splitting the model and creating a single MCDA model for each scenario (as suggested by Belton and Stewart, 2002, and illustrated by them using a hypothetical 
example). As we said before, the decision-maker felt strongly that the swing weights should be different for each scenario and splitting the model permits different weights to be attached in the value tree for each scenario.

Eliciting swing weights for the Casemurate decision provided a diverse set of weights for each scenario, with the decision maker putting more weight on profitability in the change of destination scenario (Figure 4- Exhibit A, the weight of each criterion is shown near each branch of the tree) and on liquidity in the no change of destination scenario (Figure 5 - Exhibit A). This new configuration changed the overall evaluation of options quite dramatically from the original analysis, with the withdrawal strategy now scoring higher under the latter scenario (Figure 5 Exhibit B).

Place Figure 4 and Figure 5 about here.

\section{Eliciting Performances of Strategies}

Another advantage of splitting the model is that the evaluation of options became much easier, as illustrated for the criterion Profit in Figure 4 and Figure 5 (Exhibits C). The decision maker was now focused on a single scenario when expressing his preferences: he was evaluating strategic options and not alternatives (i.e., strategy-scenario combinations) as required by the G\&W approach.

Besides, the number of combinations to be evaluated was much reduced, decreasing the cognitive complexity of the appraisal. (While the number of alternatives to be evaluated in the original G\&W approach is given by the multiplication of the number of scenarios and strategies, in the split model it is given by just the number of strategies.)

\section{Analysing Inter-Scenarios Risk and the Robustness of Options}

Goodwin \& Wright (2001) suggest that risks of a strategy could be evaluated by a risk criterion in the MCDA model, which we found hard to be properly assessed in practice, in the case study of the English broker (Figure 1 - Exhibit A).

We believe that a more transparent way of measuring the risk of adopting a strategic option is to assess the spread of performances for each option in each scenario. As shown in Figure 6, for the Casemurate decision, consolidation is a much riskier strategy than existing competencies. We suggest calling this measurement of risk as inter-scenario risk. For instance, in the same figure, the withdrawal option has an inter-scenario risk of 38 (=52 - 14). 


\section{Place Figure 6 about here.}

Another main concern of any evaluation of strategic options is to assess how robust each solution is, i.e., look for options that have a more stable performance across all scenarios. One way of assessing their robustness is to evaluate the distance, for each scenario, of a given strategy's performance when compared with the ideal performance (100). The larger the distance, the less robust the option is to a scenario. This is illustrated for the withdrawal option in Figure 6, where the distance for the change of destination is $86(=100-14)$ therefore a low level of robustness; and the distance for no change of destination is $48(=100-52)$ thus a higher level of robustness (see also Dias, 2006 for a review on robustness analysis). We will call this measurement as scenario robustness.

The measurement of robustness, as defined above, is essentially the same as the performance of a given option itself. However, we found it useful to draw the decision-maker's attention to the gap between the predicted performance and the maximum possible, i.e., focusing him on an absolute evaluation of the option, for assessing its scenario robustness.

If an overall measurement of robustness is needed for each option, we suggest adopting the robustness for the less robust scenario as the overall measure (i.e., the worst case). We will denominate this measurement as inter-scenario robustness. For example, using this indicator, the robustness for the withdrawal option, in Figure 6, is $86(=\operatorname{Max}\{[100-14],[100-52]\})$ while for the penetration option, in the same figure, is $66(=\operatorname{Max}\{[100-49],[100-34]\})$; therefore the latter has higher inter-scenario robustness. (See also Stewart 2005 for another perspective on this issue.)

\section{Generating Better Options}

Even more important than analysing the inter-scenario risk and inter-scenario robustness of strategic options, is the possibility of devising more robust and better strategies (Stewart, 1997). In both cases, MCDA can add value to a scenario planning process, as it permits a detailed appraisal of options, as conducted in the warehouse development.

ACT's Director became very attracted to the strategy of withdrawing as it had an excellent performance under the no change of destination scenario (but with a high inter-scenario risk of $38[=52-14]$, as shown in Figure 6). However, he was concerned with its low performance under the change of destination scenario. 
We started assessing, with him, why the performance of withdrawing was so poor under the change of destination. Focusing on this strategy sparked the idea that a better sale strategy could be developed - and we contacted estate agents in the area to gather more information about the potential of sale for the land. We then discovered that the land had more potential than initially assumed, due to:

1. Size - ACT managed to link together eight different estates, which involved 24 stakeholders signing the acquisition deed (producing a plot of $25 \mathrm{ha}$ ).

2. Strategic location - the land is adjacent to major motorways thus ideal for logistics use.

3. Good price - the optioned land would cost $€ 6.5 / \mathrm{m}^{2}$, compared to the $€ 10 / \mathrm{m}^{2}$ that councils pay for compulsory purchase of farm land.

These facts led the Director to revise his estimate of profit from nil to $€ 450,000$ and increased the short term liquidity to $€ 560,000$ for the withdrawal option. After re-adjusting the value function for short term liquidity (increasing its range to accommodate this new upper value) and re-eliciting the swing weights, which remained the same, the overall value of withdrawal under the change of destination scenario increased from 14 (Figure 7.a) to 27 (Figure 7.b) and in the no change of destination from 52 (Figure 7.c) to 58 (Figure 7.d).

Place Figure 7 about here.

While not making withdrawal a dominating strategy in the change of destination scenario, this improved withdrawal option made the Director more confident about this strategy, as it increased the robustness of the original option in both scenarios (compare robustness distances from Figure 7.a to Figure 7.b; and from Figure 7.c to Figure 7.d). Assessing the inter-scenario robustness for each option, it is possible to quantify such improvement, from 86 (robustness distance in Figure 7.a) for the original withdrawal, to 73 for the improved withdrawal option (robustness distance in Figure 7.b). The improved withdrawal also reduced the risk of the original option, from 38 to $31(=58-27)$ as displayed by the length of the inter-scenario risk arrows in Figure 7.c and Figure 7.d, respectively.

\section{The Day After in the Casemurate decision}

After running the extended analysis just described, ACT's Director finally felt confident in making a decision, thus we felt we finally had developed a requisite decision model (Phillips, 1984). He found that these extra tools had enabled him to better understand the problem, appraise the risk and robustness of his company's strategic options and in devising a better, more robust, strategy. He also became more and more convinced that the possibility of obtaining the 
planning permission was small, therefore favouring options that scored high in the no change of destination scenario (Figure 5).

Some months after our intervention, ACT decided to withdraw and sold the option. The profit obtained was similar to the one we had estimated in the improved withdrawal strategy. The company remains in the business and has used the profit, experience and networking gained with this deal to buy other plots of land for commercial development in Italy.

\section{Conclusions}

Despite a growing interest on the links between scenario planning and MCDA, it seems that there is a shortage of real-world interventions attempting to use both techniques in an integrated way. In this paper we described the application of the Goodwin and Wright (2001) approach, which proposes the use of Multi-Attribute Value Theory and Scenario Planning, in supporting two real-world strategic decision making processes: the future of an insurance brokerage company in England and the strategy for a warehouse development in Italy.

While the Goodwin \& Wright approach has helped in better understanding the problem and in appraising strategic options in both case studies, it has only performed well when there was a dominant option across all the scenarios (the English broker decision). A dominating option as such is, of course, an exception in strategic decision making, and the warehouse development is a good counter example.

Besides, we found that decision-makers struggled to provide preference information (criteria weights and options' performances) due to the complexity of having to analyse pairs of strategyscenario, as required by the Goodwin \& Wright approach. This result should not be a surprise, taken into account that the 15 alternatives analysed in the English broker decision is well beyond the $7 \pm 2$ magical number of Miller (Miller, 1956). We believe that this complexity may be an important factor in preventing the widespread use of the method in practice.

The second case study (warehouse development in Italy) has also shown that the integration of MCDA and scenario planning must encompass situations where there are different organisation's priorities for each scenario and a lack of a clear dominating option across all scenarios.

We recognise that such conclusions are merely tentative, drawn from only a couple of in-depth case studies, conducted as action-research interventions. Playing the dual role of researchers and facilitators brings inevitable biases involved in any participant observation research (Bryman \& Bell, 2003). While more research on the impact of the Goodwin \& Wright approach on real- 
world decisions is needed, we believe that this paper highlights the strengths of the approach, as well as some of its weaknesses.

In this sense, we have proposed some extensions to their approach. In particular we have suggested: $i$ ) splitting of the MCDA model, creating a model for each scenario, which permits an easier assessment of options and the possibility of using different weights and criteria for each scenario; $i$ ) measuring the inter-scenario risk of each option, as well as assessing its robustness to every scenarios and inter-scenario robustness; iii) devising better options, taking these two parameters (i.e., risk and robustness) into account.

While the original G\&W approach requires the use of the same weights throughout the scenarios, we believe that this is not always adequate. It clearly was not for the Casemurate decision (see also Belton \& Stewart, 2002). Besides, the literature on scenario planning hints that different stakeholders may have diverse needs in different scenarios (van der Heijden, 2005, p.278). Even considering the hypothetical example proposed by Goodwin \& Wright (2001), it is easily imaginable that the profitability could have different swing weights for each scenario. Using the same arguments, one could suggest that even the criteria may be different under different scenarios; this could be easily incorporated if one splits the model, as discusses Stewart (2005).

We believe that there are several open avenues for further research on the integrated use of Scenario Planning and MCDA (SP+MCDA). In particular, we suggest:

- Comparing different approaches for $S P+M C D A$ : Future studies could include, for example, further comparisons between the Goodwin and Wright approach and the split model in practical interventions. They also could perform experimental evaluations of the cognitive burden in eliciting preferences in both approaches. Besides, further research could be conducted on the usefulness of presenting inter-scenario risk and robustness information in supporting the appraisal of strategic options in SP+MCDA interventions.

- Contrasting SP+MCDA with traditional decision analysis. Traditional decision analysis has advocated the use of decision trees (with the attachment of probabilities to each state of nature and the calculation of expected outcomes) as the way of dealing with uncertainty. A full comparison between the use of SP+MCDA versus the use of decision trees, both at conceptual and practical levels, would be welcomed.

- Dealing with complex policies. One of the difficulties in assessing the performance of strategic options in Scenario Planning is that, in many cases, each option is indeed a policy, involving several sub-options to be considered at the same time. While this feature was not 
salient in both of our case studies, clearly it is an important issue that merits more research a possible direction is explored by Stewart \& Scott (1995) (see also, Stewart et al. (1993) and Liu \& Stewart (2004)).

As we said before, scenario planning is a widely employed decision tool for supporting strategic decision making. We believe that MCDA can play an important role in helping the evaluation of options that arise from a scenario planning intervention in practice. In particular, SP+MCDA encourage decision-makers to express their preferences for strategies taking into account future scenarios and, therefore, may support future thinking and the development of strategic values. We hope that this paper could help potential users to better appreciate the strengths of the approach, making its implementation more useful; and also that it could stimulate further research on the subject.

\section{References}

Ansoff I. 1988. Corporate Strategy. Penguin Books: Harmondsworth.

Belton V, Stewart T. 2002. Multiple Criteria Decision Analysis: An Integrated Approach. Kluwer: Dordrecht.

Brugha CM. 2004. Structure of multiple criteria decision-making. Journal of the Operational Research Society, 55: 1156-1168

Bryman A, Bell E. 2003. Business Research Methods. Oxford Univ. Press: Oxford.

Clemen RT, Reilly T. 2001. Making Hard Decisions. Duxbury: Pacific Grove, $2^{\text {nd }}$ ed.

Dias LC. 2006. A note on the role of robustness analysis in decision-aiding processes. Research Reports of INESC Coimbra, No.2/2006 (available at: http://www.inescc.pt/documentos/RR2006_02.pdf).

Durbach I, Stewart TJ. 2003. Integrating scenario planning and goal programming. Journal of Multicriteria Decision Analysis 12 (4-5): 261-271.

Eden C. 1995. On evaluating the performance of "wide-band" GDSS's. European Journal of Operational Research 81(2):302-311.

Finlay PN. 1998. On evaluating the performance of GSS: furthering the debate. European Journal of Operational Research 107(1): 193-201.

Goodwin P, Wright G. 2001. Enhancing strategy evaluation in scenario planning: a role for decision analysis. Journal of Management Studies 38(1): 1-16.

Goodwin P, Wright G. 2004. Decision Analysis for Management Judgement. Chichester: Wiley, 3rd ed.

Hammond JS, Keeney RL, Raiffa H. 1998. Even swaps: a rational method for making trade-offs. Harvard Business Review 76 (2): 137-149.

Keeney RL. 1992. Value-Focused Thinking: A Path to Creative Decision-Making. Harvard University Press: Cambridge. 
Keynes JM. 1937. The General Theory of Employment. Quarterly Journal of Economics 51(2):209-223.

Liu D, Stewart TJ. 2004. Object-oriented decision support system modelling for multicriteria decision making in natural resource management. Computers and Operations Research 31(7): 985-999.

Miller GA. 1956. The magical number seven, plus or minus two: some limits on our capacity for processing information. The Psychological Review 63: 81-97.

Montibeller G. 2005. From (and to) a new generation of multi-criteria decision analysts: an introduction to the field and a personal view on its future. In Keynote Papers - YOR 14 Conference, Meyer E (ed.) The Operational Research Society Press: Birmingham (ISBN 0 $903440334)$.

Phillips LD. 1984. A theory of requisite decision models. Acta Psychologica 56: 29-48.

Saaty T, Kearns K. 1985. Analytical Planning. Pergamon: Oxford.

Stewart TJ, Scott L, lloni K. 1993. Scenario based multi criteria policy planning for water management in South Africa. WRC Report No 296/1/93, Water Research Commission, South Africa.

Stewart TJ, Scott L. 1995. A scenario based framework for multicriteria decision analysis in water resources planning. Water Resources Research, 31(11): 2835-2843.

Stewart TJ. 1997. Scenario analysis and multicriteria decision making. In Multicriteria Analysis, Climaco J (ed.) Springer: Berlin, 519-528.

Stewart TJ. 2005. Dealing with uncertainties in MCDA. In Multiple Criteria Decision Analysis State of the Art Surveys, Figueira J, Greco S, Ehrgott M (eds.). Springer: New York, 445-470.

van der Hijden K. 2005. Scenarios - The Art of Strategic Conversation. Wiley: Chichester, $2^{\text {nd }}$ ed. 


\begin{tabular}{|c|c|c|c|c|c|c|c|}
\hline & & \multicolumn{2}{|c|}{ Scenarios } & \multicolumn{2}{|c|}{ Scenarios } & \multicolumn{2}{|c|}{ Scenarios } \\
\hline & & $\begin{array}{l}\text { Dog } \\
\text { Fight }\end{array}$ & $\begin{array}{c}\text { Mail } \\
\text { Mountain }\end{array}$ & $\begin{array}{l}\text { Dog } \\
\text { Fight }\end{array}$ & $\begin{array}{c}\text { Mail } \\
\text { Mountain }\end{array}$ & $\begin{array}{l}\text { Dog } \\
\text { Fight }\end{array}$ & $\begin{array}{c}\text { Mail } \\
\text { Mountain }\end{array}$ \\
\hline \multirow{3}{*}{ } & Status Quo $\left(\mathrm{a}_{1}\right)$ & 6 & 2 & 0 & 80 & 4.5 & 73.5 \\
\hline & $\mathrm{R} \& \mathrm{D}\left(\mathrm{a}_{2}\right)$ & 5 & 1 & 30 & 100 & 41.5 & 87.5 \\
\hline & Diversify $\left(a_{3}\right)$ & 4 & 3 & 50 & 60 & 42.3 & 76.0 \\
\hline & & \multicolumn{2}{|c|}{ a) Ranking for Max } & \multicolumn{2}{|c|}{ b) Scoring for Max } & \multicolumn{2}{|c|}{ c) Overall value for } \\
\hline
\end{tabular}

Table 1. Evaluating Strategic Options Using Scenarios (adapted from Goodwin and Wright, 2001). 


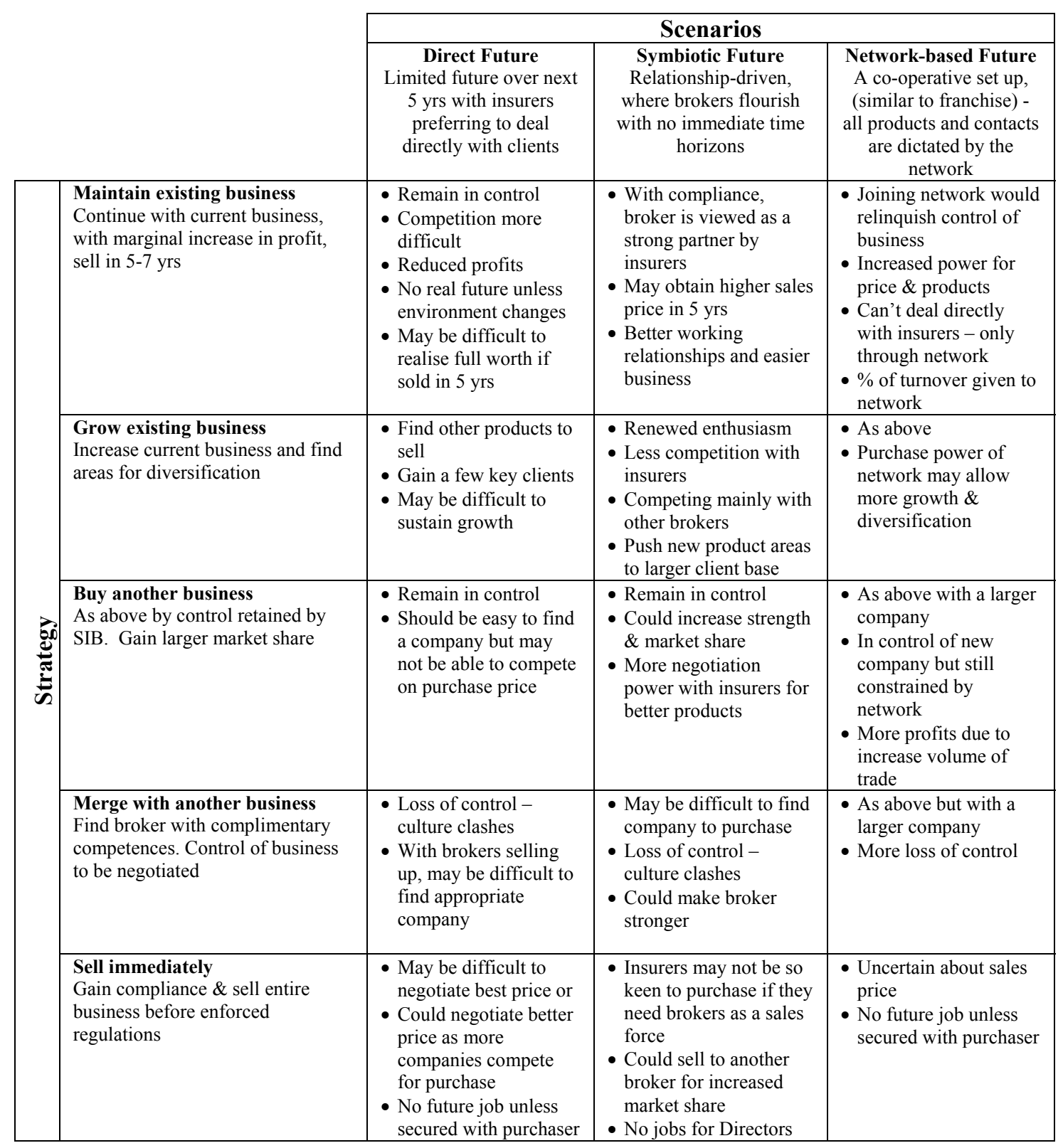

Table 2. Strategic Options and Scenarios for the Provincial Broker Decision. 


\begin{tabular}{|c|c|c|c|}
\hline & \multicolumn{2}{|c|}{$\begin{array}{c}\text { Scenarios } \\
\end{array}$} \\
\hline & & $\begin{array}{c}\text { Change of destination } \\
\text { The local council allows the start of a } \\
\text { change of destination process within the } \\
\text { duration of the option }\end{array}$ & $\begin{array}{c}\text { No change of destination } \\
\text { The local council refuses to start a change } \\
\text { of destination process within the duration of } \\
\text { the option }\end{array}$ \\
\hline \multirow{5}{*}{ कृ } & $\begin{array}{l}\text { Withdrawal } \\
\text { Sell the land before a change of } \\
\text { destination has been officially granted } \\
\text { or after it has been refused }\end{array}$ & $\begin{array}{l}\text { Sell the land at a reasonable profit } \\
\text { because the change of destination } \\
\text { seems to be possible }\end{array}$ & $\begin{array}{l}\text { - Sell the residual value of the option and } \\
\text { abandon the deal before the change of } \\
\text { destination has been officially refused } \\
\text { (better chances of making some money) } \\
\text { - Sell the residual value of the option } \\
\text { after the change of destination has been } \\
\text { officially refused } \\
\text { (worse chances to make any money) }\end{array}$ \\
\hline & $\begin{array}{l}\text { Penetration } \\
\text { Buy only some of the estates which } \\
\text { have been optioned }\end{array}$ & $\begin{array}{l}\text { - Buy only the estates whose } \\
\text { destination will be changed and } \\
\text { loose some of the option money in } \\
1.5 \text { years } \\
\text { (applies to a partial change of } \\
\text { destination) } \\
\end{array}$ & $\begin{array}{l}\text { Buy key plots of land only and loose } \\
\text { some of the option money in } 1.5 \text { years } \\
\text { (i.e. } 5 \text { ha, land lock some of the site to } \\
\text { retain control of it investing as little as } \\
\text { possible) }\end{array}$ \\
\hline & $\begin{array}{l}\text { Consolidation } \\
\text { Buy all of the land which has been } \\
\text { optioned }\end{array}$ & $\begin{array}{l}\text { - Buy all of the land and plan to } \\
\text { develop all or some of it for logistic } \\
\text { purposes or sell the land at a the } \\
\text { maximum profit as soon as the } \\
\text { change of destination process is } \\
\text { complete }\end{array}$ & $\begin{array}{l}\text { - Buy all of the land deciding in the } \\
\text { future what to do with it }\end{array}$ \\
\hline & $\begin{array}{l}\text { Use existing competencies } \\
\text { Buy all of the land and develop it in } \\
\text { ways different from logistics }\end{array}$ & $\begin{array}{l}\text { It is economically unattractive to } \\
\text { consider this option in presence of a } \\
\text { change of destination process }\end{array}$ & $\begin{array}{l}\text { - Buy all of the land in } 1.5 \text { years, apply } \\
\text { for countryside houses (the owner of } 6 \\
\text { ha of land has a right to build a house) } \\
\text { - Buy all of the land in } 1.5 \text { years and plan } \\
\text { for a countryside restaurant with a large } \\
\text { park }\end{array}$ \\
\hline & $\begin{array}{l}\text { New competencies } \\
\text { Buy all of the land and find new ways } \\
\text { different from property development } \\
\text { to generate a return from the land. }\end{array}$ & $\begin{array}{l}\text { - It is economically unattractive to } \\
\text { consider this option in presence of a } \\
\text { change of destination process }\end{array}$ & $\begin{array}{l}\text { Buy all of the land in } 1.5 \text { years and use } \\
\text { it as a vehicle deposit (van, caravans, } \\
\text { trucks, tractors) } \\
\text { - Buy all of the land in } 1.5 \text { years, vehicles } \\
\text { display area } \\
\text { - Gardening centre } \\
\text { - Buy all of the land in } 1.5 \text { years and plan } \\
\text { for countryside activities, horse riding, } \\
\text { quad bike rides, strip for motor gliders } \\
\text { - Buy the whole plot and farm the Land } \\
\text { waiting for new application cycle }\end{array}$ \\
\hline
\end{tabular}

Table 3. Strategic Options and Scenarios for the Warehouse Development. 


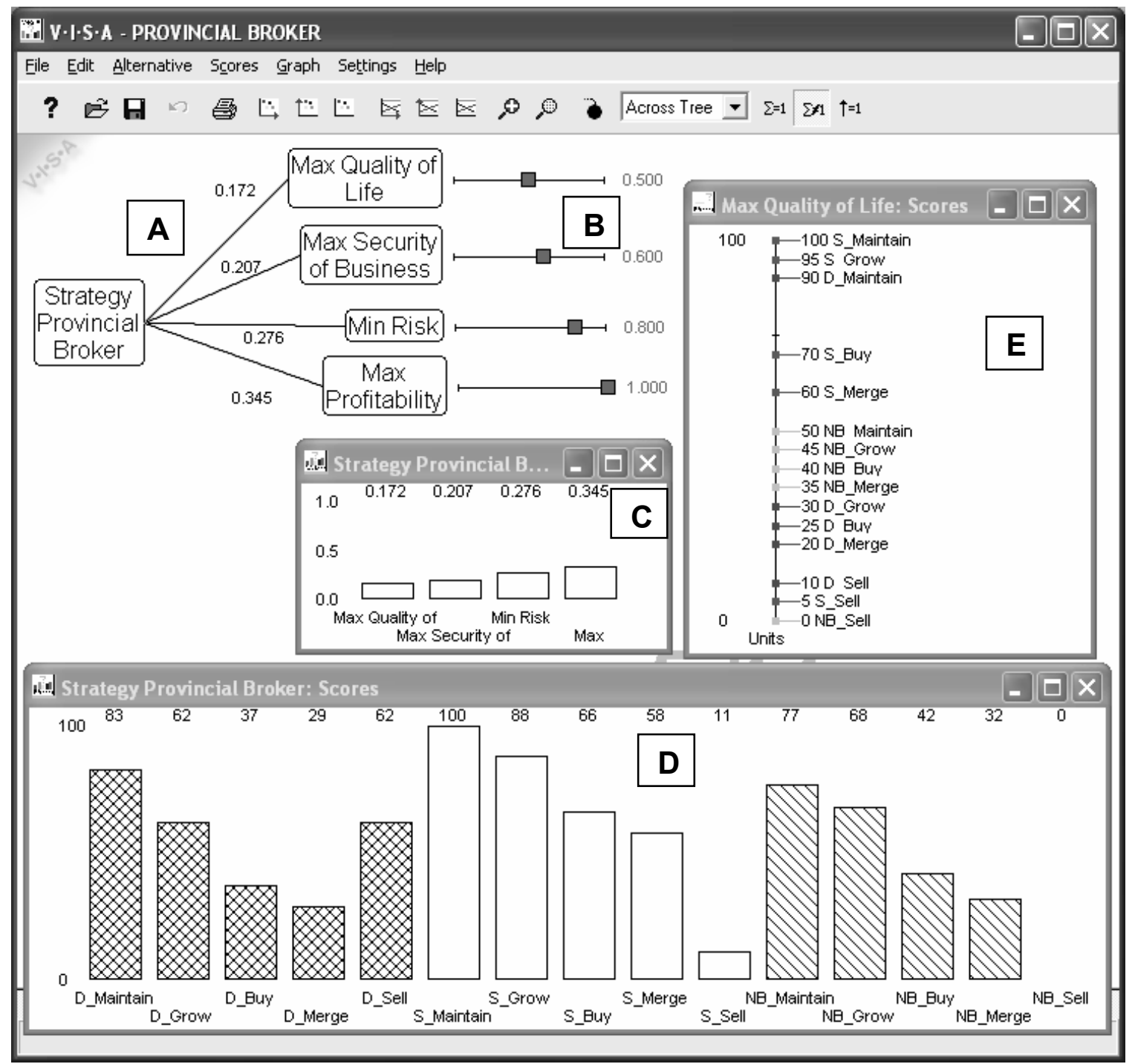

Figure 1. The Multi-Criteria Analysis for the Provincial Broker Decision using VISA. 
Montibeller et al. "Combining Scenario Planning and MCDA in Practice"

Objective: Maximise quality of life

\begin{tabular}{|c|c|c|c|c|}
\hline SWING & & \multicolumn{3}{|c|}{ SCENARIOS } \\
\hline \begin{tabular}{l|l|l|}
100 & $S M$
\end{tabular} & $\begin{array}{c}\text { Alternative } \\
\text { Strategy }\end{array}$ & Direct & Symbiotic & $\begin{array}{c}\text { Network } \\
\text { Based }\end{array}$ \\
\hline & Maintain & 90 & 100 & 50 \\
\hline & Grow & 30 & 95 & 45 \\
\hline & Buy & 25 & 70 & 40 \\
\hline & Merge & 20 & 60 & 35 \\
\hline 0 NBS & Sell & 10 & 5 & 0 \\
\hline
\end{tabular}

Objective: Minimise Risk

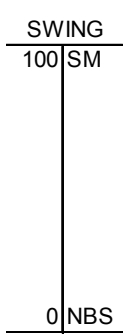

\begin{tabular}{r|r|r|r}
\cline { 2 - 4 } \multicolumn{2}{c}{} & \multicolumn{3}{c}{ SCENARIOS } \\
\hline $\begin{array}{c}\text { Alternative } \\
\text { Strategy }\end{array}$ & Direct & Symbiotic & $\begin{array}{c}\text { Network } \\
\text { Based }\end{array}$ \\
\hline Maintain & 80 & 100 & 90 \\
\hline Grow & 60 & 75 & 75 \\
\hline Buy & 20 & 60 & 40 \\
\hline Merge & 10 & 50 & 30 \\
\hline Sell & 95 & 5 & 0 \\
\hline
\end{tabular}

Objective: Maximise Security of businesss

\begin{tabular}{r|r|r|r|}
\cline { 2 - 4 } \multicolumn{4}{c}{ SCENARIOS } \\
\hline $\begin{array}{r}\text { Alternative } \\
\text { Strategy }\end{array}$ & Direct & Symbiotic & $\begin{array}{c}\text { Network } \\
\text { Based }\end{array}$ \\
\hline Maintain & 80 & 100 & 85 \\
\hline Grow & 60 & 95 & 75 \\
\hline Buy & 40 & 70 & 50 \\
\hline Merge & 25 & 65 & 35 \\
\hline Sell & 5 & 10 & 0 \\
\hline
\end{tabular}

SWING

\begin{tabular}{c|c|c}
\hline SM \\
\hline 100
\end{tabular}

0 NBS

Objective: Maximise Profitability

\begin{tabular}{r|r|r|r|}
\cline { 2 - 4 } \multicolumn{2}{c}{} & \multicolumn{3}{c}{ SCENARIOS } \\
\hline $\begin{array}{r}\text { Alternative } \\
\text { Strategy }\end{array}$ & Direct & Symbiotic & $\begin{array}{c}\text { Network } \\
\text { Based }\end{array}$ \\
\hline Maintain & 85 & 100 & 75 \\
\hline Grow & 80 & 90 & 70 \\
\hline Buy & 55 & 65 & 40 \\
\hline Merge & 50 & 60 & 30 \\
\hline Sell & 95 & 20 & 0 \\
\hline
\end{tabular}

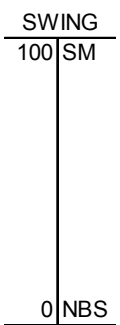

Figure 2. Evaluating Decision Alternatives in the Provincial Broker Problem. 


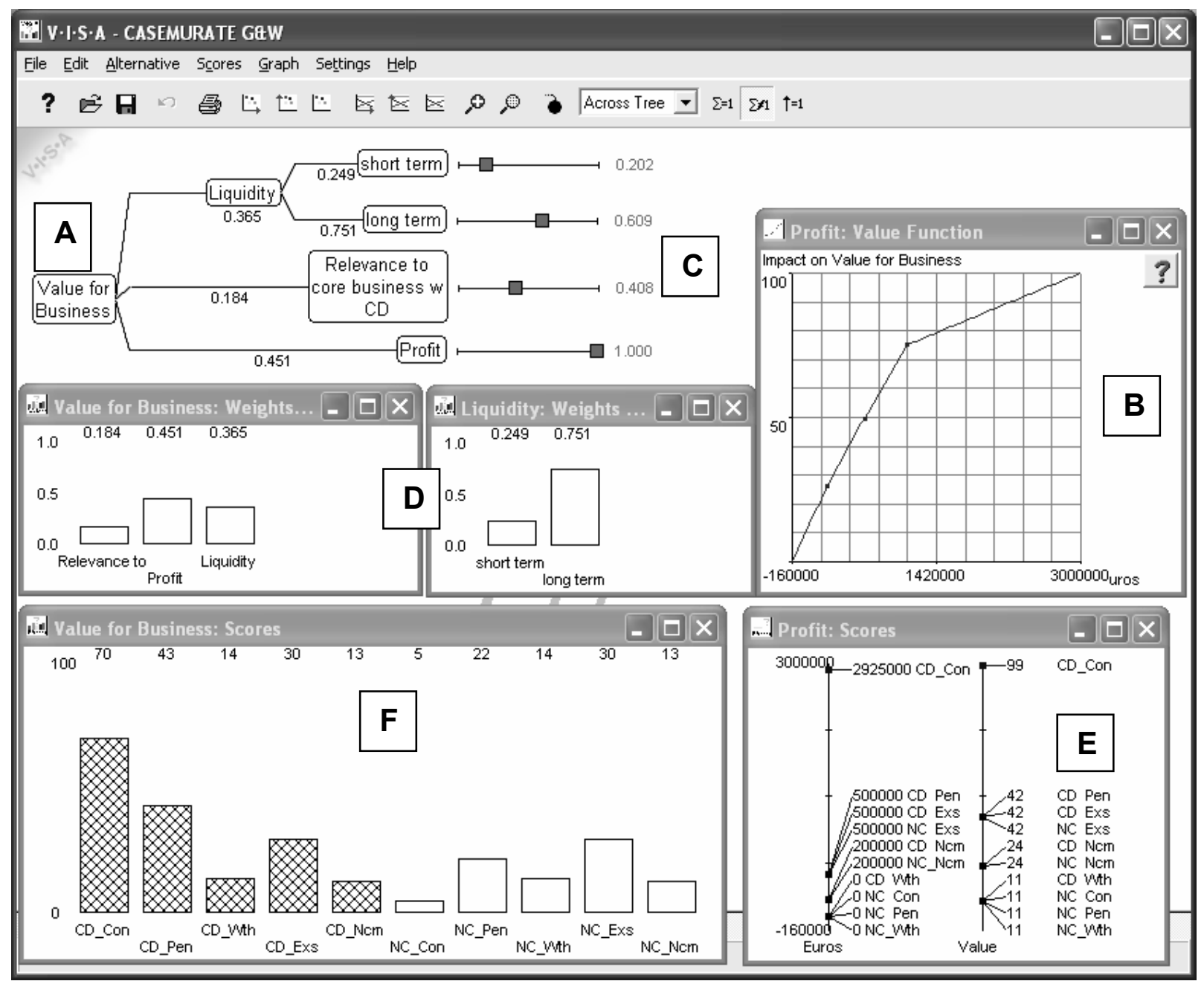

Figure 3. The Multi-Criteria Analysis for the Warehouse Development using VISA. 


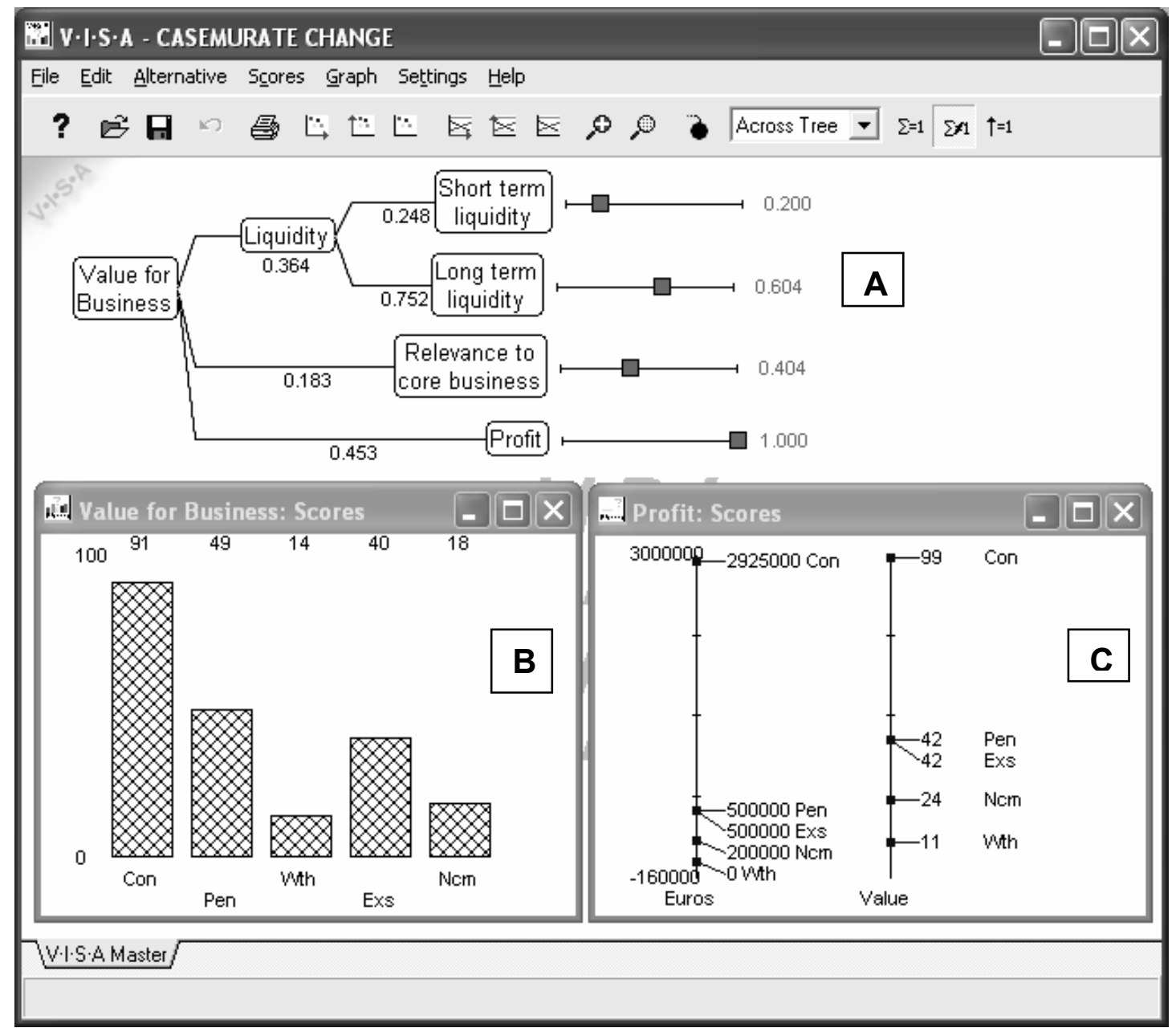

Figure 4. Split MCDA Models in the Casemurate Decision - Change of Destination Scenario. 


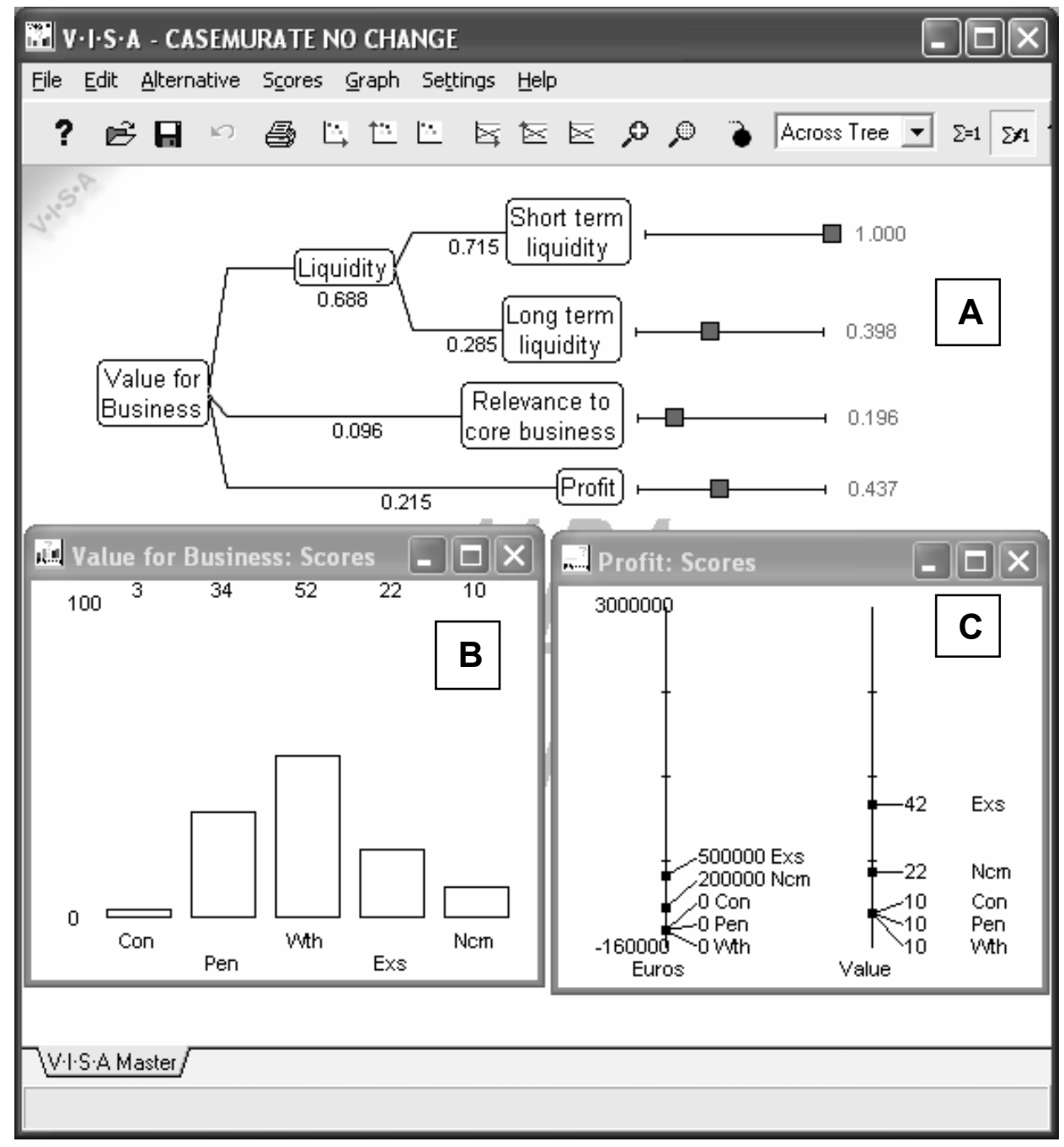

Figure 5. Split MCDA Models in the Casemurate decision - No Change of Destination Scenario. 


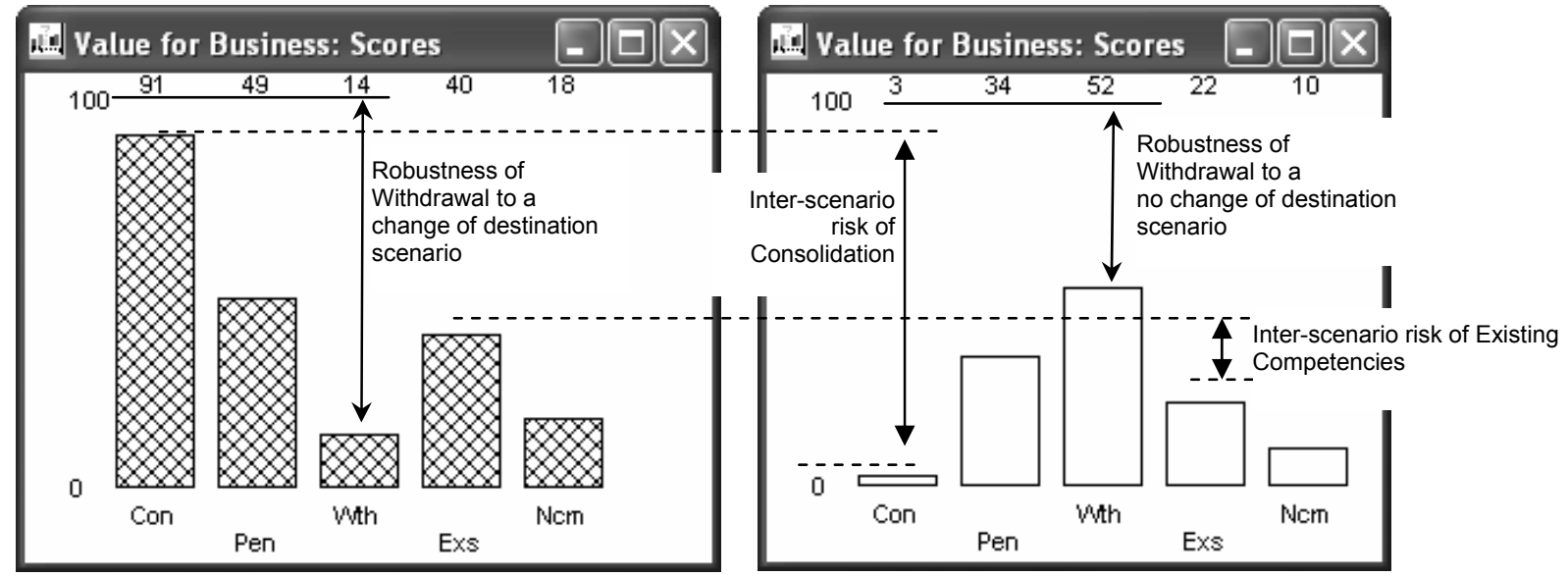

a) Change of Destination Scenario

b) No Change of Destination Scenario

Figure 6. Evaluating Performances with the Split Models in the Casemurate decision. 


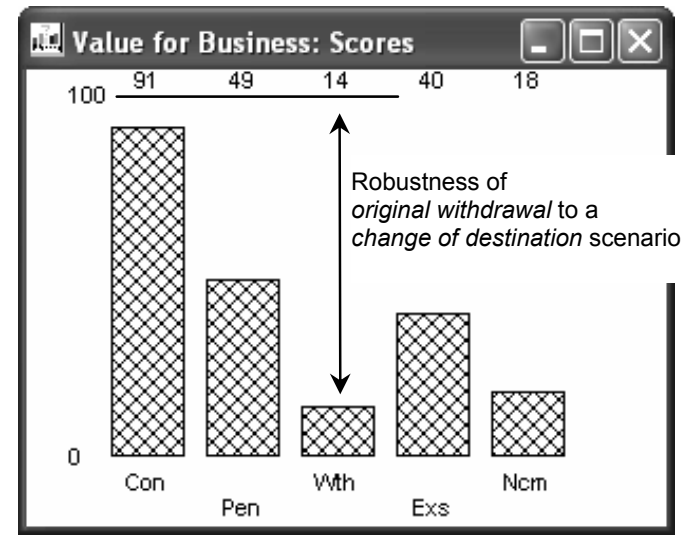

a) Change of Destination - Original Withdrawal Strategy.

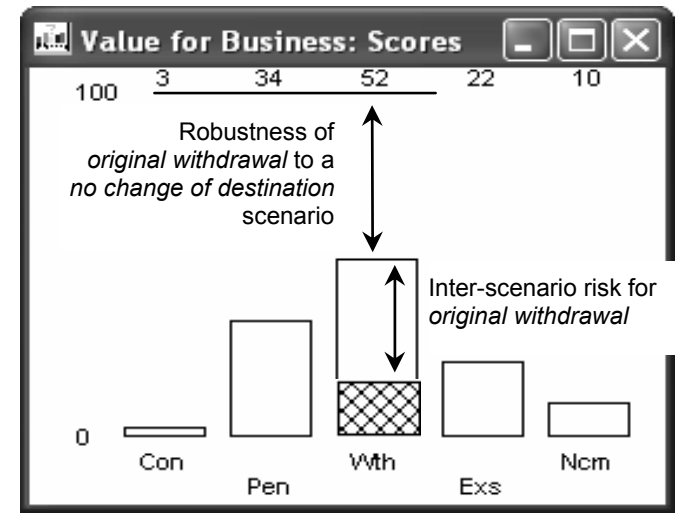

c) No Change of Destination - Original Withdrawal Strategy.

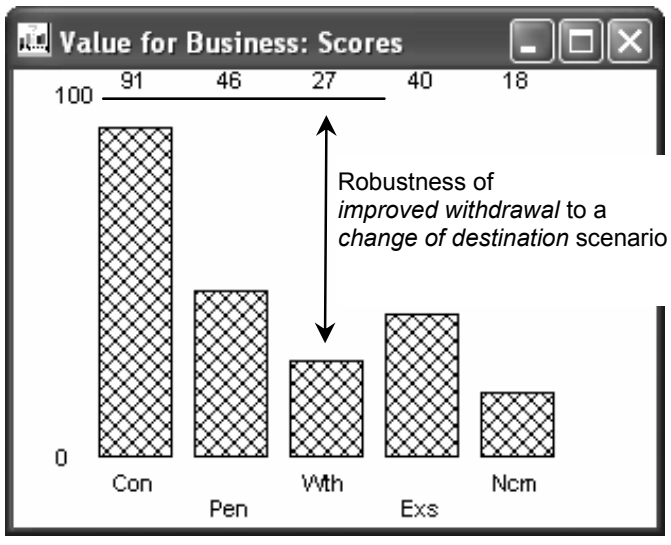

b) Change of Destination - Improved Withdrawal Strategy.

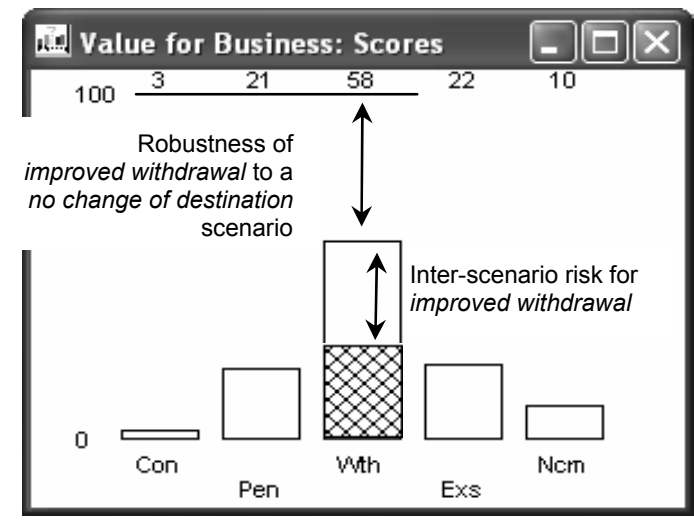

d) No Change of Destination - Improved Withdrawal Strategy.

Figure 7. Comparing the Original and Improved Withdrawal Strategies in the Casemurate Decision. 